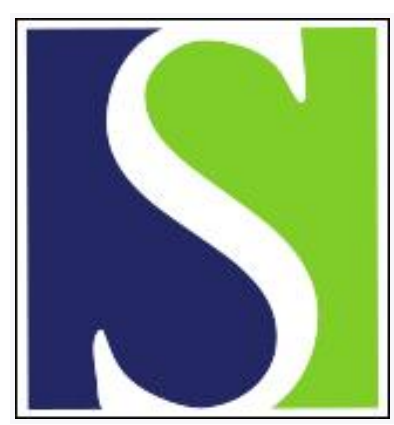

Scand J Work Environ Health 1986;12(4):351-354

https://doi.org/10.5271/sjweh.2130

Issue date: Aug 1986

\title{
Chipping hammer vibration.
}

by Clarke JB, Dalby W, Gunn JF

This article in PubMed: www.ncbi.nlm.nih.gov/pubmed/3775322

\section{(c) (1)}




\title{
Chipping hammer vibration
}

\author{
by John B Clarke, MIOA, William Dalby, John F Gunn ${ }^{1}$
}

\begin{abstract}
CLARKE JB, DALBY W, GUNN JF. Chipping hammer vibration. Scand J Work Environ Health 12 (1986) 351-354. An investigation was carried out to determine the factors influencing the vibration of chipping hammers and to find ways of reducing the vibration at the operator's hand. It showed that substantially higher vibration levels are produced at the chisel of a chipping hammer than at its handle. Typical weighted values for the two areas were 24 and $8 \mathrm{~m} / \mathrm{s}^{2}$, respectively. This finding agrees with medical observations showing that invariably the hand holding the chisel exhibits the more severe symptoms of vibration-induced white finger. A sleeve which fits onto the chisel was developed which can effect a reduction in vibration of up to $66 \%$. A prototype hammer was developed incorporating an isolating material which reduced the weighted vibration value from 7 to $3 \mathrm{~m} / \mathrm{s}^{2}$. Vibration isolating gloves were tested and resulted in an additional reduction in vibration of up to $63 \%$ when used with the chisel sleeve. A unique mounting device using rubber isolators was designed which protects the accelerometer from very intense high-frequency vibration but allows accurate measurement of chisel vibration in the frequency range of interest.
\end{abstract}

Key terms: pneumatics, vibration hazards, vibration-induced white finger.

Pneumatic chipping hammers are widely used in the steel industry, mainly for the removal of defects in steel billets and for a multitude of tasks in the foundry industry.

A project, partly sponsored by the European Coal and Steel Community, has been carried out at the Swinden Laboratories Research Centre with the aims of (i) investigating the factors influencing vibration appearing at the handles and chisels of pneumatic chipping hammers and (ii) reducing the vibration level at the operator's hands.

A number of proprietary chipping hammers were subjected to a series of standard tests so that comparisons could be made of their vibration spectra and their ability to remove metal.

Additional specific tests were undertaken to investigate the effect of the following factors on vibration: wear on the chipping hammer piston, the manner and degree of force applied to the hammer by the operator, the strength of grip exerted by the operator, and chisel sharpness.

\section{Standard testing conditions}

The guidelines embodied in the 1979 version of ISO/DIS 5349 (1) were followed during the project. Measured data were compared with the five bands of continuous exposure time per shift outlined in the standard. In addition "weighted" acceleration levels were calculated for all the data collected during the

\footnotetext{
i British Steel Corporation, Swinden Laboratories, Moorgate, Rotherham, S60 3AR, South Yorkshire, England.
}

Reprint requests to: $\mathrm{Mr}$ JB Clarke, British Steel Corporation, Swinden Laboratories, Moorgate, Rotherham, S60 3AR, South Yorkshire, England. investigation according to the recommendations in the 1983 redrafted standard.

During the tests operating conditions were strictly controlled to insure repeatability. Accordingly chipping had to be performed by an experienced operator (It was later shown that chipping performed by inexperienced personnel resulted in large variations in vibration levels.), tests had to be performed in a specially designed rig in the laboratory; and the air supply and the force applied by the operator had to be kept constant.

\section{Equipment}

The measuring equipment arrangement is shown in figure 1 . The strain-gauge bridge consisted of two gauges mounted on the upper part of the handle in an area under tension and two adjacent gauges in an area under compression when force was applied to the handle by an operator.

\section{Mechanical filter}

The purpose of the mechanical filter was to prevent the shocks produced by the hammer from reaching the accelerometer and introducing errors in the system. The proprietary Brüel \& Kjaer mechanical filter was shown to rupture within a matter of seconds of exposure to chisel vibration although it worked perfectly satisfactorily when attached to the handle. The British Steel Corporation design shown in figure 2 relies on two discs of rubber, each of which is in compression through alternate halves of the cycle; it overcomes the problem of rupture which occurs when the rubber is under tension. The frequency response of the filter is 


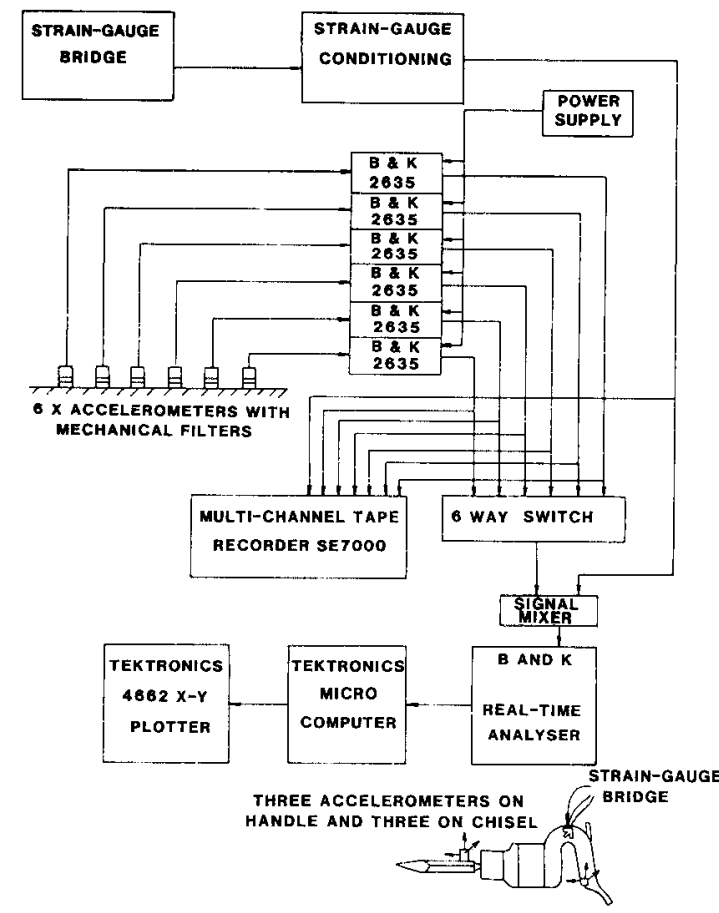

Figure 1. Multichannel vibration analysis system. (B \& $K=$ Brüel \& Kjaer).

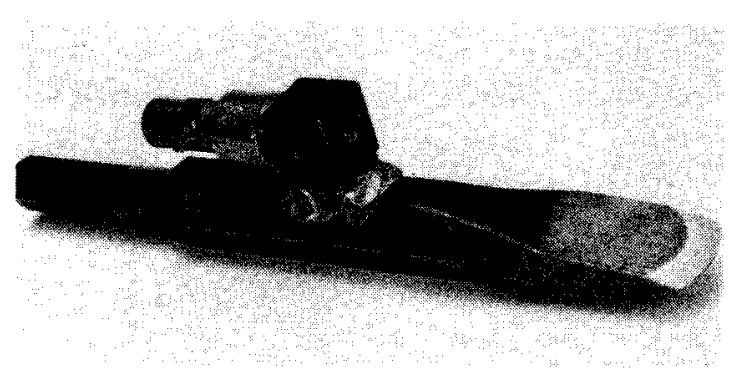

Figure 4. Chisel with accelerometer mounting block.

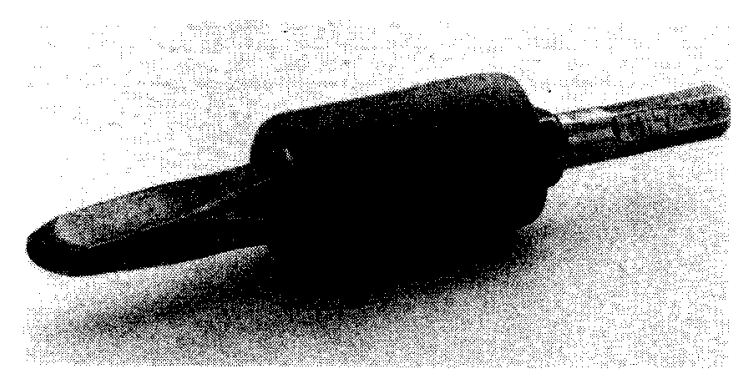

Figure 5. Chisel sleeve.

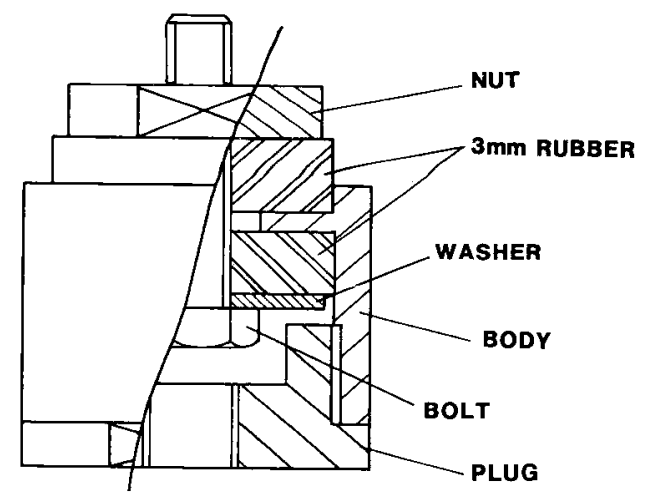

Figure 2. Cross-sectional view of the filter (in the upright mode) designed by the British Steel Corporation.

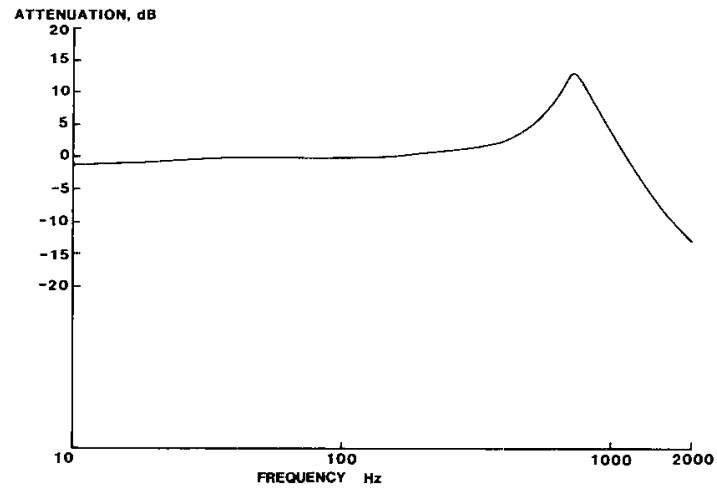

Figure 3. Frequency response of the filter depicted in figure 2 .

shown in figure 3. All the measurements were corrected to allow for the nonflat response.

\section{Chisel vibration measurements}

The final arrangement for measurement on the chisel is shown in figure 4 . Initial problems caused by the high vibration levels included the fracturing of the weld holding the block to the chisel (solved by the use of high ductility welding rods) and the unscrewing of the stud holding the accelerometer to the block (resolved by the application of "Loctite" adhesive). Even with these corrections it was possible to measure vibration in the axis parallel to the length of the chisel only.

\section{Results and conclusions}

\section{General}

All the chipping hammers tested showed substantially higher vibration levels to appear at the chisel than at the handle - typical weighted values were $24 \mathrm{~m} / \mathrm{s}^{2}$ and $7 \mathrm{~m} / \mathrm{s}^{2}$, respectively. Chisel sharpness had a dramatic effect on metal removal rate but a small 


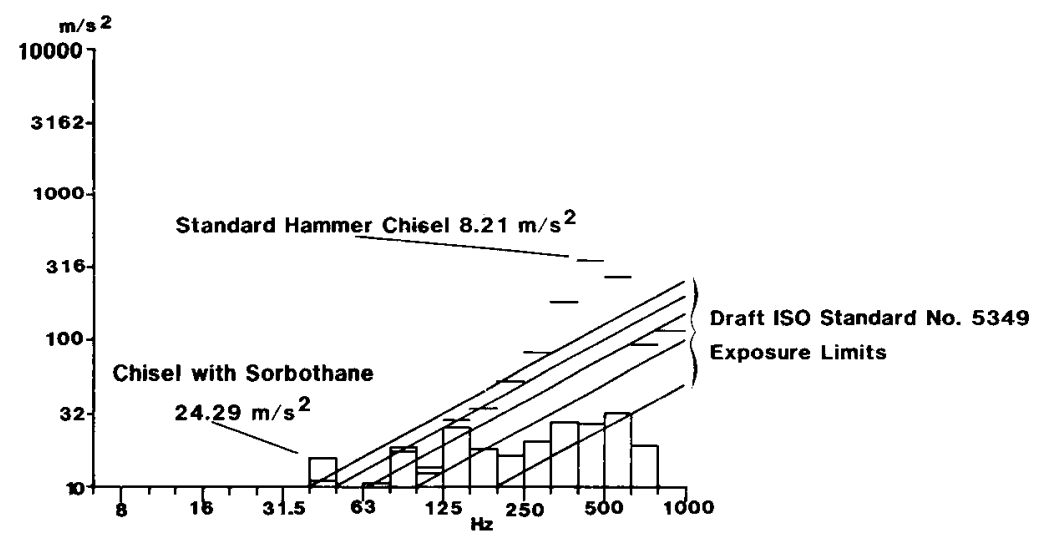

STEEL

- Sorbothane

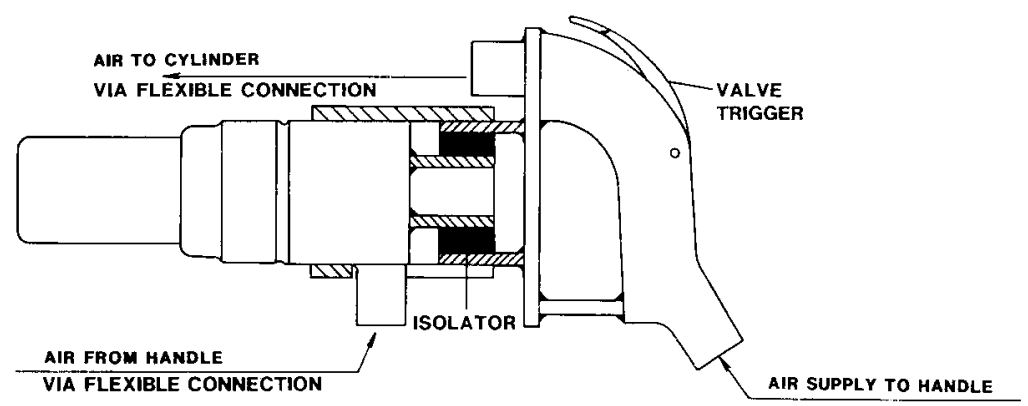

Figure 6. Comparison of spectra of the chisel with and without the Sorbothane sleeve. (ISO = International Organization for Standardization).

Figure 7. Cross-section of the Sorbothane Mk III hammer.

Figure 8. Comparison of spectra of the MacDonald D1 (standard) and Sorbothane Mk III hammers. (ISO = International Organization for Standardization). effect on vibration. The resilience of the material supporting the steel workpiece being chipped had little effect on the vibration.

\section{Isolating sleeve}

A sleeve made from a polyurethane elastomer (marketed under the name Sorbothane) which fits onto a chisel was developed (figure 5). Figure 6 shows that it effects a substantial reduction in vibration. The sleeve further provides a reduction in heat transfer to the hands, which can cause discomfort during certain operations.

\section{Vibration-reduced hammers}

A prototype hammer incorporating the use of Sorbothane, between the handle and barrel, was developed (figure 7). Figure 8 shows the degree of vibration reduction over that compared with a conventional hammer with a corresponding reduction in the weighted value from 7 to $3 \mathrm{~m} / \mathrm{s}^{2}$. 


\section{Gloves}

Gloves lined with polyurethane elastomer were tested while being worn by the chipping hammer operator. When the gloves were used in conjunction with the chisel operating sleeve, reductions of up to $63 \%$ greater than that afforded by the sleeve alone were achieved.

\section{Acknowledgments}

This paper has been published with the permission of Dr KJ Irvine, Director of Research, British Steel Corporation.

\section{References}

1. International Organization for Standardization. Guidelines for the measurement and assessment of human exposure to hand-transmitted vibration. Geneva 1979. (ISO/DIS 5349). 